\title{
O corpo da palavra não é fixo deixa-se tocar pelo tempo e seus espaços
}

\author{
Isabel Setti
}

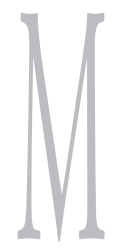

ylene Pacheco morreu há poucos meses. A beleza imponente das vozes trabalhadas por ela nos deixou antes ou permanece como eco distante, referência de qualidade que ainda não encontrou corpo de igual grandeza.

Compartilho hoje com Mônica Montenegro o lugar que Mylene honrou por mais de 20 anos na Escola de Arte Dramática. A notícia de sua morte agitou em meu espírito questôes presentes desde que, tendo sido sua aluna por dois anos, concluí minha formação nesta mesma escola em 1981, e comecei a dar aulas primeiro de interpretação, depois de voz. Essas questôes ganharam corpo, urgência e novos contornos a partir de 2000, ano em que assumi a responsabilidade de um trabalho que, desde Maria José de Carvalho, professora da EAD ainda antes de Mylene, foi traço marcante na definição de identidade da escola.

Tudo em Mylene era imponente. Sua voz maravilhosa, fruto de técnica precisa, sua competência, seu rigor, suas exigências, sua figura, sua maquiagem, suas sobrancelhas, seus brincos, as cores com que se vestia, a intensidade e constância de seu interesse pelos trabalhos de seus alunos mesmo quando formados, o orgulho quando suas vozes ganhavam projeção e se distanciavam da voz banalizada e coloquial contra a qual ela dedicava seus dias.

Quando a conheci, no final da década de 1970, já se havia criado um vácuo entre as qualidades maduras e indiscutíveis de seu estilo forjado em anos de estudo, trabalho e certezas e as necessidades ainda sem definição, ainda geradoras de mais perguntas que respostas, de um teatro faminto por naturalidade e conexões, na ação e na subjetividade, mais claras entre ator, personagem e espetáculo.

Vácuo entre a impostação que havia servido a deuses e heróis e a voz natural, cotidiana, do cidadão que agora queria ocupar a cena. Esse cidadão despojado, avesso do herói, do tamanho de suas incertezas, penetrou a cena buscando uma relação de intimidade, consigo mesmo e com o seu público, na expectativa de compreensão do significado de suas ações em um mundo muito próximo.

As grandes mudanças que se sucediam no modo de ocupação dos palcos aumentavam a distância entre a preparação vocal como a conhecíamos e as necessidades da nova cena.

Isabel Setti é atriz e professora da Escola de Arte Dramática da USP. 
O Arena havia alterado a relação do ator com o espaço, com a palavra, com a apropriação dos significados, com o público. O Oficina criara novos paradigmas, desmontando estruturas, abrindo o espaço do palco para a manifestação das urgências de seus atores cidadãos criadores. Antunes varrera do tablado tudo o que não era corporificado por seu ator e renomeava a função e o alcance de uma poética que se produzia no corpo a corpo diretor/ator, fazendo nascer sua própria impostação, fruto das experiências que realizava com jovens atores.

Tínhamos sido tocados pelas notícias das vivências libertadoras do Living Theatre. De muito longe, era ainda tudo muito longe, escutávamos o eco das experiências de Grotowski e seus atores do Teatro Laboratório, capazes de grande potência expressiva em suas experiências para provocar o "renascimento" do ator e potencializar o "encontro" com seu público.

Nos toca-discos, desde o final dos anos sessenta, a Tropicália explodia irreversivelmente a idéia de pureza de qualquer linguagem, anunciava nossa completa mestiçagem, retomava o exercício da antropofagia e levava ao palco corpos em si mesmos e por si mesmos musicais.

Vivi, com minha geração, quase um desinteresse pelo trabalho com a voz, como se ele representasse um peso, uma ligação ao passado, uma espécie de fardo. Trabalhar a voz confundia-se demasiadamente com a idéia de impostação. Palavra que parecia conter uma atitude em que não nos reconhecíamos mais. Percebíamos o miúdo alcance de nossas vozes, mas precisávamos dar passagem a uma nova sonoridade. Que apenas intuíamos. Nós a desejávamos comprometida com as urgências e com o corpo novo que se estava construindo.

Líamos Artaud. E experimentávamos o fascínio pelo dilaceramento da palavra e pela explosão dos significados. Foi este, aliás, um tempo de desmoronamento dos sonhos e práticas mais queridos pelos que "desejavam mudar o mundo". Todas as palavras - e eram muitas com que inventávamos um mundo livre e belo e em paz precisavam mesmo ser rasgadas para que pudéssemos produzir uma linguagem viva e, com ela, novo jeito de habitar o mundo. Precisávamos aceitar a realidade tão poderosamente múltipla, tão brutalmente difícil de ser compreendida. Era preciso buscar novo sentido para a palavra transformação. As vísceras expostas de um Artaud, mais imaginado que conhecido, pareciam a única linguagem razoável.

Eu sentia grande admiração pela potência, pela clareza, pela bela ressonância das vozes de Mylene, mas experimentava desconforto com a falta de naturalidade daquela expressão, com a padronização da entonação e, principalmente, com a ausência de contato daquela técnica com a experiência da coisa dita. A abordagem dos textos clássicos, com os quais encorpávamos nossas vozes, criava antes vazios de significação do que ação vocal efetiva, tanto em nosso íntimo como na relação com o público.

Estou certa de que este desajuste, este desconforto, não era só meu. $\mathrm{O}$ vazio entre nossa formação vocal e as novas exigências estéticas perdurou, pelo menos, por uma década, talvez mais. Foi ao longo da década de 1990 que começaram a ganhar corpo social, entre nós, as experiências em torno de uma voz que se pensa orgânica, identificada com o indivíduo que, nela, se reconhece e se manifesta. Essa voz, em conexão com a experiência do presente, está começando a se fazer ouvir, articulando-se devagar, amadurecendo, conquistando precisão, espaços de ressonância e projeção a partir da experiência de integração do sujeito expressivo a si mesmo, aos novos espaços e aos diferentes pactos que estabelece com seu público.

As últimas décadas testemunharam transformaçōes profundas no pensamento sobre o corpo. De sua preparação, objetivando o aprendizado de seqüências codificadas de movimentos, para a construção de um corpo disponível, plástico, articulado, potente para a expressão do sujeito que dançava, enraizado em seu universo afetivo e cultural, foram incontáveis as contribuições.

O conhecimento científico, os conceitos e práticas da fisioterapia e da neurologia, a cons- 
ciência da relação entre ossos, músculos e dinâmica das vísceras, tudo isso invadiu as salas de dança e os estudos sobre o corpo cênico.

A aproximação das filosofias e práticas orientais ampliou nossa percepção do indivíduo como ser íntegro, conectado a seu centro vital tanto quanto às forças, não mais só políticas, que atuam sobre ele.

A clareza de que a própria ocupação do espaço é gesto tão expressivo quanto político aprofundou a responsabilidade da atuação que, com a assimilação das novas dinâmicas, passa a resultar do compromisso de todos os aspectos do ser do intérprete no mundo.

O próprio conceito de corpo deixou de ser o de um instrumento do sujeito, compreendendo-se, enfim, como sujeito ele próprio. Senão, quem é o sujeito que dele se diferencia?

Quando Kazuo Ono esteve aqui pela primeira vez, compreendemos a eloqüência da ação do tempo criando o corpo expressivo. E vimos, perplexos, como nossa própria idéia de corpo expressivo era limitada e opressiva. Em Kazuo, nem o corpo ideal do bailarino, nem o bailarino a serviço de uma composição organizada fora dele, nem mesmo o bailarino e sua interioridade como tema. Mas experiência em tempo presente, silêncio expressivo, entrelaçamento do corpo ao tempo e aos vazios, a vida em processo no instante mesmo da comunicação. A história do homem e de sua gente expressa nas marcas de seu corpo revelado. A ação do tempo e do espaço sobre o indivíduo torna-se, ela própria, tema, expressão, significado. $\mathrm{O}$ bailarino disponível para deixar-se atuar por forças superiores a ele e a seus comandos.

E, então, Pina Bausch. Trazendo a primeiro plano as características muito pessoais, idiossincráticas, a história, a cultura e, sobretudo, a experiência dos sentidos de cada um de seus bailarinos. $\mathrm{O}$ tecido expressivo produzindo-se na investigação sobre a vida que nutre e sustenta a ação cênica. A palavra constituindo-se no instante mesmo da descoberta, misturando-se ao ato de concepção da cena. E a qualidade de interpretação intimamente associada à capacida- de de reagir, com abandono e inteireza, aos jogos e projetos cênicos. O improvável, os contrastes, a falha.

A música também vinha popularizando experiências radicais de desconstrução dos conceitos tonais, aproximando-se de outros modos, novos ou antiqüíssimos, de pensar-se, de produzir-se.

A voz, a palavra falada, vivia seu momento de introspecção, de introversão, acuada, com um lugar secundário, de coadjuvante nas experiências profundas, nos largos passos com que o corpo ia derrubando suas paredes.

Sonorizávamos dinâmicas, soávamos, tímida ou visceralmente, nossas paixões, mas, pobres de técnicas que sustentassem a ousadia da experiência, ou ficávamos vocalmente aquém dela, portanto sem integridade expressiva, ou feríamos sem piedade nossas pregas vocais e os tímpanos e paciência dos espectadores.

Mylene dera forma à voz dos atores. Não formara professores de voz. Não era sua função nem seu objetivo. Os cursos de fonoaudiologia dedicavam-se às patologias do aparelho fonador. No geral, não trabalhavam a estética da voz e, principalmente, desconheciam seu múltiplo universo poético.

Os diretores das escolas de teatro, que em São Paulo se multiplicavam, tinham clareza sobre a necessidade de investir sobre a voz de seus alunos, mas não sabiam onde encontrar professores que pudessem corresponder às exigências deste trabalho, fosse com o olhar representado por Mylene Pacheco, fosse pelas fonoaudiólogas recém-formadas que apenas começavam a se aproximar do teatro, fosse por alunos, recémformados pelas escolas de teatro mais consistentes, que procuravam identificar as delicadas conexões da voz com idéias, afetos e músculos.

Foi nesse contexto que comecei a dar aulas de interpretação, meu foco de interesse. O problema apresentou-se de imediato e cristalino: os alunos correspondiam aos estímulos com intensidade, graça e, até, visceralidade, sempre nos aspectos a que nos habituamos a chamar de corporais. Quando desejavam ou 
eram solicitados a manifestar-se vocalmente, abria-se uma fissura que desintegrava seu corpo expressivo.

Essa fissura passou a ser meu desafio. A voz do aluno funcionava bem nos exercícios fonético/musculares, a consciência de suas possibilidades vocais expandia-se, o interesse pelas dinâmicas de vibração, ressonância, projeção e ocupação do espaço amadurecia. Experiências interessantes eram realizadas, acordando uma nova sensibilidade para o universo sonoro. Descobertas, por vezes emocionadas, se sucediam. A voz revelava sua potência transformadora.

Mas, no momento de avançar da investigação para a cena, lá estava a fissura. Ou o aluno falava baixinho, pequeno, no esforço de aproximar o texto de si mesmo - retirando-se, neste ato, do espaço que deveria fazer vibrar ou a fala parecia pertencer a outra pessoa, em completa desconexão com a experiência de aparente plenitude que eu presenciara quando o foco não estava na palavra.

Assim, sem haver feito conscientemente esta escolha, tornei-me professora de voz. Talvez as perguntas que eu me fazia naquele momento fossem perguntas necessárias, urgentes. O fato é que, de início, eu tinha muito pouco além destas perguntas e, ainda assim, via crescer um interesse pelas experiências que as aulas ofereciam.

Compreendi que era preciso reencontrar os princípios elementares do pensamento de meus mestres como a dança continuava a fazer com os princípios do balé clássico. Perceber como reagiam no contato com as múltiplas desconstruçôes e ousadias expressivas que ganhavam a cena e identificar que novos objetivos pediam licença para direcionar as investigações.

$\mathrm{Na}$ prática cotidiana das aulas ou salas de ensaio, identifiquei importantes deslocamentos de foco que, em tentativas, erros, acertos, repetições, foram definindo uma atitude nos procedimentos de investigação vocal que experimento agora esboçar e que, talvez, venha a ser útil para a organização ao menos de nossas perguntas, no momento em que os limites entre tea- tro, dança, música, artes plásticas e o que mais colabore para efetivar o ato de comunicação perdem definição e se deixam transformar pela fusão de diferentes linguagens e pela experiência da performance.

Momento em que a ciência reconhece a inteligência das emoções e dos sentidos.

Momento em que a própria casa do fazer teatral, onde antes a voz ressoava, vê cair suas paredes e passa a confundir-se com a própria cidade.

\section{Da voz do sujeito para o sujeito da voz: a voz como reverberação da vontade}

Estávamos habituados a trabalhar a voz do ator como um aspecto de seu ser, para potencializala e abrir-lhe possibilidades expressivas. Hoje temos a compreensão de que é o próprio sujeito expressivo que, ao manifestar-se, está se constituindo como sujeito no mundo. $\mathrm{O}$ foco, portanto, passa a ser sua ação vocal, capaz de criar o espaço poético e estabelecer a dinâmica das relações.

Nessa interação do indivíduo/ator com a palavra, com seu interlocutor e com o espaço, potencializar a voz passa a identificar-se com o exercício de apropriação de significados, com a responsabilidade daquilo que é dito, com a vitalidade da presença do intérprete no espaço que se modifica por sua ação. Não é a fala do sujeito que nos interessa aqui, mas a ação que esta fala desencadeia, o corpo, também sonoro, que se estrutura para falar e como se constitui o sujeito enquanto fala.

A clareza do que quer ser dito, as razōes que o ator tem para dizê-lo e o pacto que estabelece com seu público no momento da fala são os maiores pilares de sustentação da voz. Assim, a utilização dos instrumentos e condutas técnicas tem por finalidade expandir o alcance da ação do indivíduo cuja voz modificará a si mesmo, definirá o espaço que ocupa, testemunhará seu posicionamento no mundo e efetivará pactos claros, e sempre renovados, com o espectador. 
Não se trata, portanto, de forjar uma voz para um sujeito segundo um padrão e uma expectativa exterior ou anterior a ele, mas em enriquecer, com procedimentos de investigação também técnicos, a construção da identidade, também vocal, do mesmo.

“...pois não há nada que altere tanto as qualidades materiais da voz como possuir um conteúdo de pensamento: isso influi na sonoridade dos ditongos e na energia das labiais."

Essas palavras de Proust em $\grave{A}$ Sombra das Raparigas em Flor dão colorido a uma percepção já madura em sala de aula. Sempre que o gesto vocal se produz como reverberação da vontade daquele que o realiza, manifestando a qualidade de presença deste homem no mundo, as possíveis limitações técnicas se resolvem com consciência e músculos.

A clareza de objetivos organiza a qualidade da presença, em corpo, voz e movimento, para a eficácia da ação que se quer realizar.

Por outro lado, se esta clareza, se esta vontade, se esta apropriação de sentido não ocorre, nem a técnica mais elaborada poderá ocupar, com integridade, seu lugar. Poderá mascarar e, neste ato, esconder, silenciar ainda mais o homem por trás da máscara.

Portanto, ao invés de eleger uma forma para dizer algo, o ator provocará a ação vocal, com todas as suas surpresas, enquanto se ocupa com o que tem a dizer, com o que acontece em si quando diz e com as reverberaçóes, no outro, da ação desencadeada por sua palavra. Cada objetivo constrói um corpo, também vocal, para atingir sua meta.

Se, ao constituir realidades poéticas, a fala do ator objetiva criar laços, configurar relações, testemunhar acontecimentos, desencadear experiências em seus espectadores, como não considerar, então, um treinamento que privilegie e atue sobre sua vontade, sobre suas responsabilidades, sobre as dinâmicas corpo/sonoras que se constituem no presente da ação, sobre sua qualidade de presença, sobre o equacionamento das relações e das estruturas de poder tão fortemente expressas na fala?

\section{Da máscara da voz impostada para a multiplicidade de depoimentos}

Uma voz impostada pode constituir uma máscara de alta definição, desobrigando o sujeito do contato de nervos expostos com seu público. Em contraponto, a dilatação de uma presença natural e humana pode ganhar altura poética e efetivar fortes laços com o espectador.

Há, quase sempre, uma confusão entre os hábitos de fala de um ator e a idéia que ele faz de sua voz, ecoando, muitas vezes, as impressões de seu círculo de relações. A voz de alguém é uma unidade complexa, um universo em que interagem tanto as manifestaçôes do presente como as múltiplas e potenciais ampliações em extensão, timbres, intensidades, volumes e experimentações poéticas de que aquela pessoa é capaz. A voz é testemunho do passado tanto quanto indicador do porvir. Ela é sua história, sua manifestação presente e seu potencial. A realidade da voz é seu movimento.

Parece-me necessário que, antes de tomar para si modelos, o ator adquira consciência da natureza de sua expressão e de seus hábitos de fala, analisando-os no contexto que lhes deu origem. Compreendendo as atitudes, a história, a geografia, os ritmos, os conteúdos afetivos, a riqueza expressiva que estes hábitos traduzem. E, principalmente, os vínculos que sua fala expressa e revela. Assim, ele perceberá que está trabalhando sobre uma herança e que suas escolhas são mais que vocais.

Por outro lado, enquanto os velhos hábitos vão cedendo lugar à viva plasticidade, um forte processo de auto-conhecimento é desencadeado e a voz potencial do ator vai sendo revelada.

Não se trata de adquirir novos hábitos ou de "aprender" uma voz, mas de liberta-la de tudo que a fixa, mecaniza, obscurece, escraviza.

Trata-se de ampliar a potencialidade técnica pela investigação que não dissocia expe- 
riência muscular dos afetos e das idéias. Assim, o campo, antes ocupado pela impostação, alimentar-se-á agora da dilatação do próprio sujeito expressivo. A expansão de sua presença e o consequente alcance de sua voz serão fruto da multiplicidade de experiências de contato do ator com suas vozes e suas poéticas ou, ainda, com as atitudes vocais das figuras humanas sobre quem ele fará seu depoimento.

$\mathrm{O}$ ator fará contato consigo mesmo, e com sua gente, pela interioridade, pela experiência, pela observação, pelo jogo, pela imaginação, pela fantasia. Deste contato, resultará seu testemunho. Sua fala que é única. Na multiplicidade que a constitui.

O poder de ressonância e projeção da voz deste ator integrado a si mesmo resultará, portanto, não de impostação conforme determinado modelo, mas de sua capacitação para responder íntegra e criativamente aos estímulos, tanto no aprendizado de diferentes técnicas como no contato com sua própria interioridade. Assim, não se perderá, na dinâmica de ocupação do espaço, a riqueza de seu testemunho pessoal.

\section{Voz é corpo: da voz no corpo para o corpo da voz}

A técnica não é neutra. Não há inocência nas escolhas que determinam os procedimentos de criação de uma obra. E isto é também verdade quando se trata de ossos ou músculos. A arte do fazer, a eleição de um conjunto de procedimentos, o modo de estruturar, aquecer e alongar o corpo, o caminho para abrir os espaços da sonoridade, a qualidade sonora perseguida, o modo de habitar o espaço, a especificidade do engajamento solicitado para a realização dos trabalhos, a relação entre todos os parceiros ou entre parceiros e condutores do processo, todas estas direções já contém em si a totalidade do fenômeno teatral.

Se construímos atmosferas buscando tessituras poéticas, se partimos da multiplicidade de significados, se experimentamos uma co- nexão com o poder encantatório da palavra, se vamos para o palco com o texto decorado ou levamos o papel nas mãos ao ensaiar a cena, cada ponto de partida inaugura um plano de investigação que produzirá diferentes relações entre o sujeito que fala, aquilo que ele diz e a experiência do espectador.

A separação das disciplinas, especialmente Corpo, Voz e Interpretação, se nos ajuda a focar aspectos da investigação e organiza procedimentos, por outro lado cria forte dificuldade para o aluno de integrar, num todo dinâmico, a riqueza e complexidade de suas experiências. Essa separação colabora para a permanência da idéia de que há um corpo que produz uma voz e não um corpo que, em sua integridade, é também sonoro. O conjunto de ossos, tecidos, cavidades, cartilagens e músculos que produzem o som está em plena conexão com os outros ossos, tecidos, cavidades, cartilagens e músculos que precisam atuar solidariamente na produção deste som. Há sempre um processo de transformações que se realizam em cadeia até alcançar a totalidade da ação expressiva.

Esse processo pode ser acionado, por exemplo, por dinâmicas de estruturação óssea, mas os procedimentos ditos vocais são, eles também, estruturadores do corpo e podem dar início à organização em cadeia que, naturalmente, só se realiza quando o princípio de investigação é o comprometimento da totalidade do sujeito expressivo.

Assim, as ações vocais não serão produzidas pelo esforço de um grupo de músculos, o que tende a sobrecarregar a sonoridade. Sua intensidade expressiva resultará de uma reorganização integral do ator para a consecução de seu objetivo.

Somos ainda demasiadamente reféns de um conceito de corpo como parte visível, carnal, muscular e óssea da pessoa. Mas já sabemos que a vontade que anima o sujeito, a condição de seu espírito, suas emanaçóes, o arfar de sua respiração, o pulso e o tônus de sua fala, o modo como integra o espaço e o habita, o objetivo de suas ações, são também corpo. A presença e as 
reações que a presença desperta dizem respeito a uma grandeza que é fruto da interação de todos estes elementos.

Clareza de objetivos, consciência da estrutura óssea, correspondência entre musculatura externa e interna, disponibilidade das vísceras, exploração das cavidades, alento, fluxos de energia, tônus e foco funcionam como uma orquestra que dilata o campo expressivo do ator, dando realidade à experiência poética. E o corpo da voz age.

Para ampliar, otimizar as características vocais de um desempenho, as qualidades perseguidas resultarão de um corpo que se reorganiza na mesma medida em que produz seu duplo sonoro. Este, por sua vez, revela o conjunto de ações que o torna possível.

O corpo sonoro, ao projetar-se no espaço, já não se pode diferenciar da estrutura que o sustenta. As emanações produzidas, agindo sobre o espectador, dão testemunho desta totalidade.

\section{A poesia está no "entre"}

A linguagem se realiza no momento em que o "entre" se constitui: este campo, esta dimensão que se abre entre aquele que fala e aquele que escuta, entre aquele que propõe as imagens e aquele que as deixa ecoar em si produzindo significados. O espaço poético não pertence a nenhum dos jogadores. Instaura-se. É energia que conecta. É compartilhamento.

No teatro, lugar por excelência de construção e experimentação de linguagens, nada está circunscrito ao indivíduo. A dinâmica da comunicação acontece ao criar-se o campo ativo entre dois atuadores, entre atuador e público ou entre atuadores e público. São composições diferentes os "entres" que estas relações criam, mas trata-se sempre da dimensão poética instaurando-se e multiplicando significados entre um e outro, entre uns e outros.

A voz, portanto, não é em si: "Como estava a minha voz?"; "O que você achou da minha voz?".
Se, como espectador, é dela que me ocupo, então o ato não se deu, a comunicação não aconteceu.

A voz está a serviço do ato que se quer compartilhar. Daquilo que se modifica, naquele que fala e naquele que escuta, pela ação que a fala contém. A voz é o tecido, a trama do espaço poético a ser compartilhado.

Ela é fruto da totalidade do ser em escuta. Do estado pleno de atenção. De nervos expostos, disponíveis para reagir aos estímulos em tempo presente.

Criou-se um campo de ação entre todos os presentes? A fala materializou-se em ação vocal? $\mathrm{O}$ foco migrou daquele que fala para o acontecimento que, fazendo vibrar o espaço, contém e modifica a todos?

Então a voz cumpriu o seu papel.

\section{A experiência da palavra}

Apoios, dilatação dos espaços internos, tridimensionalidade.

Fluxos de energia, direcionamento do sopro, sonoridade das vogais, precisão das consoantes.

A boca, seus espaços, sua mobilidade. Flexibilidade e plasticidade da articulação.

Apropriação da palavra e das idéias. Ressonância. Assertividade.

Presença: uma espacialidade dentro de outra espacialidade; uma espacialidade gerando e conectando espacialidades.

Identificação do sujeito que fala à coisa dita. Necessidade. Urgência.

Escuta ativa: maturar a palavra no silêncio. Deixar-se tocar por seu corpo vivo. Instinto.

Relação do intérprete com as poéticas de seu mundo. Testemunho.

Aprender a ouvir.

Dar-se a conhecer.

Vocalizar a experiência de ocupação da polis. 


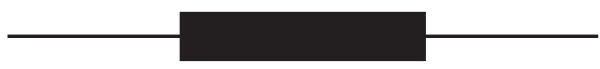

